\title{
Colitis and Crohn's Foundation (India): a first nationwide inflammatory bowel disease registry
}

\author{
Ajit Sood ${ }^{1}$, Kirandeep Kaur ${ }^{2}$, Ramit Mahajan ${ }^{1}$, Vandana Midha ${ }^{3}$, Arshdeep $\operatorname{Singh}^{1}$, Sarit Sharma ${ }^{4}$, \\ Amarender Singh Puri ${ }^{5}$, Bhabhadev Goswami ${ }^{6}$, Devendra Desai ${ }^{7}$, C. Ganesh Pai ${ }^{8}$, Kiran Peddi ${ }^{9}$, Mathew Philip ${ }^{10}$, \\ Rakesh Kochhar $^{11}$, Sandeep Nijhawan ${ }^{12}$, Shobna Bhatia ${ }^{13}$, N. Sridhara Rao ${ }^{14}$ \\ Departments of ${ }^{1}$ Gastroenterology, ${ }^{2}$ Pharmacology, ${ }^{3}$ Internal Medicine, and ${ }^{4}$ Community Medicine, Dayanand Medical College and Hospital, \\ Ludhiana, ${ }^{5}$ Department of Gastroenterology, Govind Ballabh Pant Hospital, New Delhi; ${ }^{6}$ Department of Gastroenterology, Gauhati Medical \\ College, Guwahati; ${ }^{7}$ P. D. Hinduja Hospital and Medical Research Centre, Mumbai; ${ }^{8}$ Department of Gastroenterology, Kasturba Medical College, \\ Manipal; ${ }^{9}$ Citizens Centre for Digestive Disorders, Hyderabad; ${ }^{10}$ Lisie Institute of Gastroenterology, Kochi; ${ }^{11}$ Department of Gastroenterology, \\ Post Graduate Institute of Medical Education and Research, Chandigarh; ${ }^{12}$ Department of Gastroenterology, Sawai Man Singh Medical College, \\ Jaipur; ${ }^{13}$ Department of Gastroenterology, King Edward Memorial Hospital, Mumbai; ${ }^{14}$ Purnachandra Gastroenterology Institute, Guntur, \\ India
}

Background/Aims: The national registry for inflammatory bowel disease (IBD) was designed to study epidemiology and prescribing pattern of treatment of IBD in India. Methods: A multicenter, cross-sectional, prospective registry was established across four geographical zones of India. Adult patients with ulcerative colitis (UC) or Crohn's disease (CD) were enrolled between January 2014 and December 2015. Information related to demographics; disease features; complications; and treatment history were collected and analyzed. Results: A total of 3,863 patients (mean age, 36.7 \pm 13.6 years; 3,232 UC [83.7\%] and 631 CD [16.3\%]) were enrolled. The majority of patients with UC $(n=1,870,57.9 \%)$ were from north, CD was more common in south $(\mathrm{n}=348,55.5 \%)$. The UC:CD ratio was 5.1:1. There was a male predominance (male:female $=1.6: 1)$. The commonest presentation of UC was moderately severe $(n=1,939,60 \%)$ and E2 disease $(n=1,895,58.6 \%)$. Patients with CD most commonly presented with ileocolonic $(n=229,36.3 \%)$ inflammatory $(n=504,79.9 \%)$ disease. Extraintestinal manifestations were recorded among $13 \%$ and $20 \%$ of patients in UC and CD respectively. Less than $1 \%$ patients from both cohorts developed colon cancer $(\mathrm{n}=26,0.7 \%)$. The commonly used drugs were 5-aminosalicylates (99\%) in both UC and CD followed by azathioprine (34.4\%). Biologics were used in only $1.5 \%$ of patients; more commonly for UC in north and CD in south. Conclusions: The national IBD registry brings out diversities in the 4 geographical zones of India. This will help in aiding research on IBD and improving quality of patient care. (Intest Res 2021;19:206-216)

Key Words: Inflammatory bowel disease; National registry; Colitis, ulcerative; India; Crohn disease

\section{INTRODUCTION}

Disease registries are clinical tools to help in collection, analysis, and publication of data from the real world. ${ }^{1}$ Over the last few decades, disease registries have become an integral part

Received December 9, 2019. Revised January 27, 2020

Accepted January 29, 2020.

Correspondence to Ajit Sood, Department of Gastroenterology, Dayanand Medical College and Hospital, Tagore Nagar, Ludhiana 141001, India. Tel:

+91-981-5400718, Fax: +91-161-2302620,E-mail: ajitsood10@gmail.com of healthcare system and are considered as powerful as randomized controlled trials (RCTs). Patients included in these registries are those treated in routine clinical practice, where there are no pre-defined study criteria and are followed up for a longer duration than the RCTs. ${ }^{2}$ National population-based registries for various diseases can give the opportunity to analyze the external validity of RCTs and aid investigators in evaluation of natural disease course, response to treatment and survival rates. ${ }^{2}$ Therefore, the use of national registries for generating real-world data in various diseases, especially those 
with changing epidemiology is of great value.

Inflammatory bowel disease (IBD), comprising ulcerative colitis (UC) and Crohn's disease (CD), which were once considered to be diseases of Western world have now become common in developing countries..$^{3-9}$ A recent study reporting the incidence and prevalence of IBD from 8 regions in Asia and Australia (Asia Pacific Crohn's and Colitis Epidemiologic Study, ACCESS) showed an increasing incidence of IBD in these countries. ${ }^{5}$ In India, the incidence of UC $(6.02 / 100,000)$ is much higher than other Asian countries. ${ }^{6}$ Similarly, an increasing incidence of CD has been reported by a multicenter study from India. ${ }^{10}$ Despite this increasing incidence of IBD in India, prospective longitudinal population or hospital-based data is deficient.

A need for a national level Indian IBD registry to generate real-world data was thus felt and present multicenter registry was designed to study the demographics, clinical presentation, and prescribing patterns for management of UC and CD in 4 geographical zones of India.

\section{METHODS}

\section{Registry Setting}

The Indian IBD registry was initiated by Colitis and Crohn's Foundation (CCF) India as a multicentric prospective registry involving referral centers from 4 geographical zones (north, east, west, and south) of India. Eleven centers (4 north, 1 east, 2 west, and 4 south) were enrolled from January 1, 2014 to December 31, 2015. The Organizing Committee of the IBD Registry included gastroenterologists from these referral centers. A team comprising of a gastroenterologist, nurse and data analyst was set up at every center and weekly meetings were organized to assess the enrollment process. The nodal center of the registry was Department of Gastroenterology, Dayanand Medical College and Hospital, Ludhiana. Patients were managed at their respective centers without interference from the registry team. The study was approved by ethics committee of nodal center Dayanand Medical College and Hospital, Ludhiana on behalf of all the participating centers (IRB No. 2015112). The study was performed conforming to the Helsinki declaration of 1975, as revised in 2000 and 2008. Informed consents were obtained.

\section{Study Population}

All adult patients ( $>18$ years) attending the IBD clinics or those requiring hospitalization at the various referral centers were enrolled for the registry. Patients were excluded if they were younger than 18 years, had unclassified IBD, or refused to provide consent.

\section{Disease Definition}

IBD was diagnosed based on the Copenhagen (clinical, laboratory, radiological, and pathological), as follows: ${ }^{11,12}$ (1) Clinical: history suggestive of chronic inflammatory diarrhea, abdominal pain, vomiting, weight loss and fever. While blood and mucous in stools and rectal symptoms (urgency, frequency, and tenesmus) favored diagnosis of UC; abdominal pain, malnutrition, and perianal disease favored CD. Physical examination focused on assessing pallor, cachexia, abdominal tenderness, and perianal involvement. (2) Laboratory evaluation: routine hematological and biochemical tests, evidence of anemia, thrombocytosis, elevated erythrocyte sedimentation rate (ESR), and C-reactive protein (CRP), hypoproteinemia/ hypoalbuminemia and absence of infective causes on stool routine examination and culture. (3) Endoscopy: colonoscopic evidence of contiguous involvement in form of mucosal edema, erythema, erosions/ulcers, granularity, friability, pseudopolyp formation favored diagnosis of UC. Skip areas of involvement, transmural involvement, longitudinal deep ulcers with cobble-stoning, upper gastrointestinal, small bowel, and perianal involvement favored CD. (4) Radiology: computed tomography or magnetic resonance enterography were done in patients with complicated UC and for assessing the extent of $\mathrm{CD}$. Whenever upper gastrointestinal involvement was suspected in CD, based on clinical history and examination, patients were subjected to imaging modalities like barium meal follow through or computed tomography enterography to evaluate the extent of disease. Radiological findings favoring CD were small bowel wall thickening, increased mesenteric vascularity, strictures and/or fistulae and/or perianal disease. (5) Pathology: endoscopic biopsies showing chronic inflammation with cryptitis and crypt abscesses favored UC, while non-caseating granulomas with negative staining for $\mathrm{Myco}$ bacterium tuberculosis were suggestive of CD.

\section{Disease Classification}

The Montreal classification was used to further classify UC and CD. ${ }^{13,14}$

\section{Disease Severity}

Disease severity was defined by the Mayo score in patients with $\mathrm{UC}^{15}$ and Harvey Bradshaw Index in patients with CD. ${ }^{16}$ 


\section{Data Recording}

Prospective data collection was done at all the centers. Patient initials, age, gender, religion, socioeconomic status, whether smoker (ever or never), history of appendectomy, disease history along with time since onset of disease, symptoms, family history of IBD (both UC and CD; in both first degree [parents/ siblings] and second degree [paternal/maternal uncles/aunts and cousins] relatives), extraintestinal manifestations (EIMs), disease severity and extent, drugs prescribed and requirement of surgery were noted. Each case was recorded once despite multiple visits to the hospital during the study period. The subjects were allowed to withdraw from the IBD disease registry at any time with a written request.

\section{Statistical Analysis}

Data were described in terms of range; mean \pm standard deviation, median, frequencies (number of cases) and relative frequencies (percentages) as appropriate. For comparing categorical data, chi-square test was performed and exact test was used when the expected frequency was less than 5 . A probability value ( $P$-value) less than 0.05 was considered statistically significant. All statistical calculations were done using SPSS version 21.0 (IBM Corp., Armonk, NY, USA) and Stata version 12.0 (StataCorp., College Station, TX, USA).

\section{RESULTS}

\section{Demographics}

A total of 3,863 patients (3,232 UC and 631 CD) were enrolled (north, 2,034; east, 260; west, 745; south, 824). There were zonal differences in the number of patients and the type of IBD. More than half of the UC patients $(n=1,870,57.9 \%)$ were enrolled from the northern cohort, while more than half of the CD patients $(\mathrm{n}=348,55.5 \%)$ were from the southern cohort. No cases of CD were reported from the eastern cohort. The overall UC:CD ratio was 5.1:1 (north, 11.4:1; east, 260:0; west, 5.3:1; south, 1.4:1). Though UC was more common than CD in all 4 zones, the UC:CD ratio was 8 times higher in north (11.4:1) than south (1.4:1). A male preponderance was noted in all the cohorts. The overall male-to-female ratio was 1.6:1 (UC, 1.5:1; CD, 2.2:1). The mean age at diagnosis of IBD was $36.7 \pm 13.6$ years, being $37.5 \pm 13.2$ years for UC patients and $35.8 \pm 14.3$ years for CD patients. A majority of IBD patients were young adults in the age group of 18-40 years (UC: $n=1,772,54.8 \%$; CD: $\mathrm{n}=387,61.3 \%)$. At the time of enrollment, nearly half of the patients had onset of symptoms within 1 year $(n=1,969$,
50.9\%; UC: $\mathrm{n}=1,627,50.3 \%$; CD: $\mathrm{n}=342,53.4 \%)$ and one-third had symptoms for $1-5$ years ( $\mathrm{n}=1,350,34.9 \%$; UC: $\mathrm{n}=1,154$, 35.7\%; CD: $n=196,31.1 \%)$. Fourteen percent patients $(n=542$; UC: $\mathrm{n}=461,13.9 \%$; CD: $\mathrm{n}=91,14.4 \%$ ) were symptomatic for more than 5 years.

A positive family history of IBD was reported in 120 patients (3.1\%; UC: $\mathrm{n}=100,3.1 \%$; CD: $\mathrm{n}=20,3.2 \%$ ). History of smoking was elicited in $4.2 \%$ and $5.9 \%$ of the total UC and CD patients respectively. The highest percentage of smokers in the UC and CD cohorts were from eastern cohorts and southern cohorts respectively. History of appendectomy was noted in 167 (4.3\%) patients (UC: $\mathrm{n}=145,4.5 \%$; $\mathrm{CD}: \mathrm{n}=21,3.3 \%$ ).

A difference in religious practices was also noted among the different zones. Overall, a majority of IBD patients were Hindus ( $\mathrm{n}=2,591,67 \%)$ followed by Sikhs $(\mathrm{n}=840,21.8 \%)$, Muslims $(\mathrm{n}=235,6.1 \%)$ and Christians $(\mathrm{n}=187,4.8 \%)$. Among the UC patients, two-thirds of patients ( $\mathrm{n}=2,166,67.0 \%)$ were Hindus (north: $\mathrm{n}=1,056,56.5 \%$; east: $\mathrm{n}=220,84.6 \%$; west: $\mathrm{n}=557$, 89.0\%; south: $\mathrm{n}=333,70.0 \%)$. The second most common religions were Sikhism (40.1\%) in northern cohort; Islam in eastern (9.2\%) and western (6.5\%) cohorts and Christianity (17.2\%) in southern cohort. Among CD patients, Sikhism (51.2\%) was most common in northern cohort, and Hinduism in western (86.6\%) and southern (71.0\%) cohorts. More than three-fourths of the IBD patients $(\mathrm{n}=2,664,68.9 \%$; UC: $\mathrm{n}=2,170,67 \%$; CD: $\mathrm{n}=494,78.3 \%$ ) belonged to upper middle and lower middle classes and only a few $(\mathrm{n}=280,7.2 \%$; UC: $\mathrm{n}=258,8 \% ; \mathrm{CD}: \mathrm{n}=22$, $3.5 \%$ ) belonged to the upper class (Table 1).

\section{Clinical Presentation}

\section{1) Ulcerative Colitis}

Patients with UC most commonly had E2 disease, $(\mathrm{n}=1,895$, $58.6 \%)$ followed by E3 $(n=772,23.9 \%)$ and E1 $(n=565,17.5 \%)$ disease. Zonal differences in presentation have been summarized in Table 2. A majority of patients with UC had moderately severe active colitis $(n=1,939,60.0 \%)$. Regional variations were noted in disease severity. Nearly three-fourths of the patients in northern cohort had moderately severe disease $(n=1,394$, $74.5 \%$ ) while a similar proportion in eastern cohort had mild disease $(n=198,76.2 \%)$. In the southern cohort, nearly half of the patients had moderately severe disease $(n=232,48.7 \%)$, closely followed by severe disease $(n=201,42.2 \%)$. Thirteen percent of the patients with UC $(n=422)$ had EIMs. These are summarized in Table 2. EIMs were more common in age groups $18-40$ years ( $14.3 \%$ ) and age $>60$ years $(14.9 \%)$; females $(15.7 \%)$; and severe disease (17.9\%) (Table 3$)$. Only 22 patients $(0.7 \%)$ 


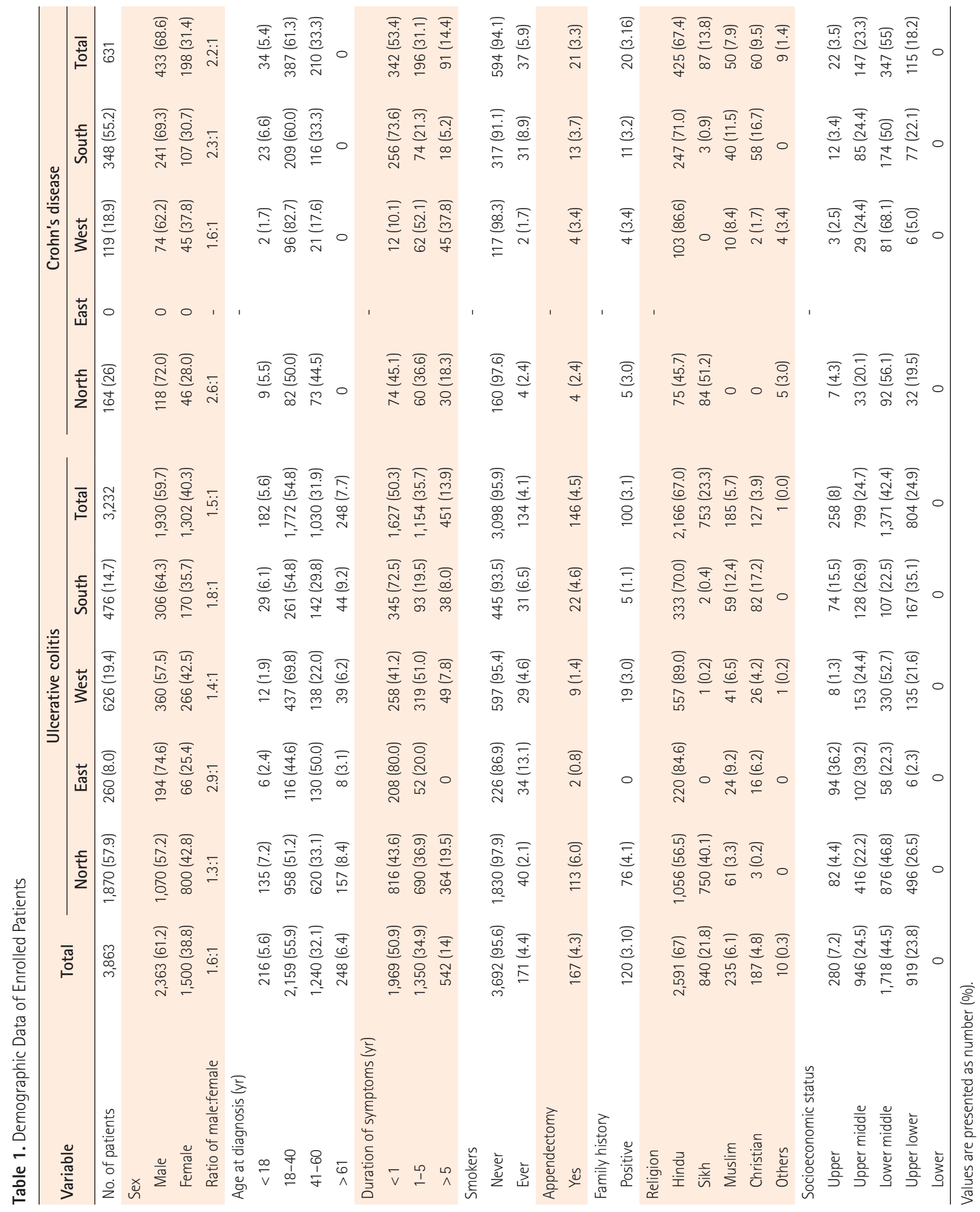




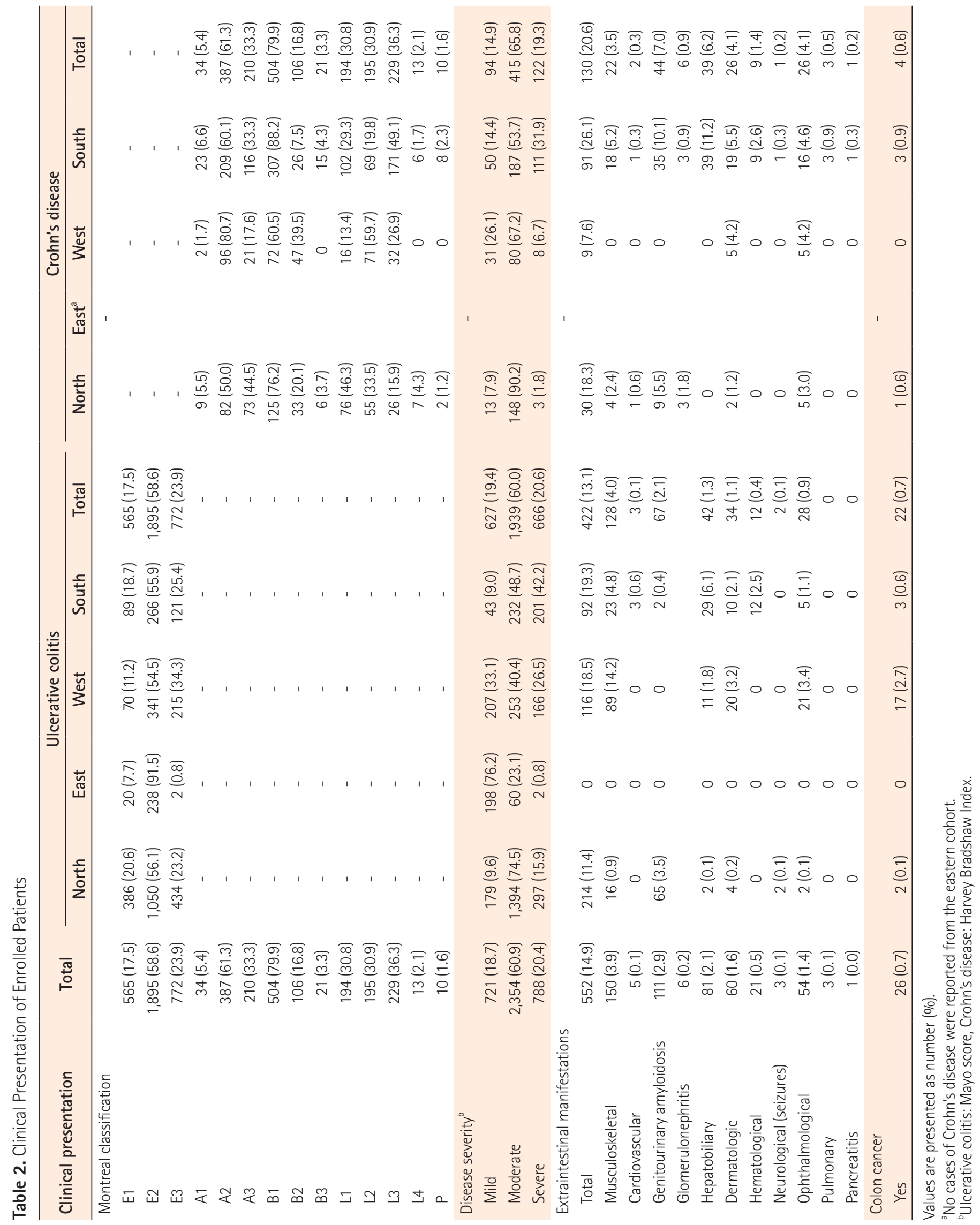


Table 3. Extraintestinal Manifestations

\begin{tabular}{|c|c|c|c|c|c|}
\hline \multirow{2}{*}{ Variable } & \multicolumn{2}{|c|}{ Extraintestinal manifestations } & \multirow{2}{*}{ Total } & \multirow{2}{*}{$\chi^{2}$} & \multirow{2}{*}{$P$-value } \\
\hline & No & Yes & & & \\
\hline \multicolumn{6}{|l|}{ Ulcerative colitis } \\
\hline $18-40$ & $1,688(86.4)$ & $266(13.6)$ & 1,954 & & \\
\hline $41-60$ & 910 (88.3) & $120(11.7)$ & 1,030 & & \\
\hline Female & $1,097(84.3)$ & $205(15.7)$ & 1,302 & & \\
\hline Male & $1,713(88.8)$ & $217(11.2)$ & 1,930 & & \\
\hline Extent & & & & 16.895 & 0.000 \\
\hline Left sided & $1,643(86.7)$ & $252(13.3)$ & 1,895 & & \\
\hline Moderate & $1,688(87.1)$ & $251(12.9)$ & 1,939 & & \\
\hline Severe & 547 (82.1) & 119 (17.9) & 666 & & \\
\hline Immunosuppressant & & & & 36.233 & 0.000 \\
\hline None & $1,897(84.6)$ & $346(15.4)$ & 2,243 & & \\
\hline Yes & 913 (92.3) & $76(7.7)$ & 989 & & \\
\hline \multicolumn{6}{|l|}{ Crohn's disease } \\
\hline Age at diagnosis (yr) & & & & 12.745 & 0.002 \\
\hline $1-16$ & 33 (97.1) & $1(2.9)$ & 34 & & \\
\hline $17-40$ & $315(81.4)$ & $72(18.6)$ & 387 & & \\
\hline Colon+small intestine & $185(80.8)$ & 44 (19.2) & 229 & & \\
\hline Perianal & $10(100)$ & 0 & 10 & & \\
\hline Proximal gastrointestinal & $13(100)$ & 0 & 13 & & \\
\hline Small intestine & $139(71.6)$ & $55(28.4)$ & 194 & & \\
\hline Disease presentation & & & & 12.092 & 0.002 \\
\hline Fistulizing & $19(90.5)$ & $2(9.5)$ & 21 & & \\
\hline Inflammatory & 386 (76.6) & $118(23.4)$ & 504 & & \\
\hline Stricturing & $96(90.6)$ & $10(9.4)$ & 106 & & \\
\hline Disease severity & & & & 44.051 & 0.000 \\
\hline Mild & 85 (90.4) & $9(9.6)$ & 94 & & \\
\hline Moderate & $345(83.1)$ & 70 (16.9) & 415 & & \\
\hline Severe & 71 (58.2) & $51(41.8)$ & 122 & & \\
\hline Immunosuppressant & & & & 0.340 & 0.560 \\
\hline None & $234(80.4)$ & 57 (19.6) & 291 & & \\
\hline Yes & $267(78.5)$ & $73(21.5)$ & 340 & & \\
\hline
\end{tabular}

Values are presented as number (\%). 
had history of colon cancer.

\section{2) Crohn's Disease}

Among the CD patients, the most common age at diagnosis was $17-40$ years $(n=387,61.3 \%)$. Overall, the commonest disease location was L3 (36.29\%), followed by L1 (30.74\%), and L2 (29.31\%). However, there was a significant regional variation in the disease location $(P<0.001)$. The most common locations were L1 (46.3\%); L2 (59.7\%), and L3 (49.1\%) in the northern, western and southern cohorts respectively. Fourfifths of the patients presented with non-stricturing, non-penetrating (B1) disease $(n=504,79.9 \%)$. The disease was moderately severe in a majority of patients $(\mathrm{n}=415,65.8 \%)$. Severe disease was seen in 122 out of 631 patients (19.3\%), and the maximum number $(111 / 122,90.1 \%)$ were from the southern cohort. One-fifth of the patients $(n=130,20.6 \%)$ developed EIMs. EIMs were most commonly reported from the southern cohort ( $\mathrm{n}=91,26.1 \%)$. When analyzed, EIMs were more commonly associated with age $>40$ years $(27.0 \%)$; ileal disease (28.4\%); non-stricturing and non-penetrating (B1) disease behavior (23.4\%); and severe disease (41.8\%) (Table 3). Only 4 out of 631 patients $(0.6 \%)$ had history of colon cancer.

\section{Prescribing Pattern and Treatment}

Of a total 3,863 IBD patients, 3,825 (99.0\%) received aminosalicylates. The distribution of the use of various groups of drugs is mentioned in Table 4. Among the UC patients, 1,354 patients (41.9\%) received steroids. A majority of these patients were from the northern $(\mathrm{n}=781,41.8 \%)$ and western $(\mathrm{n}=335,53.5 \%)$ cohorts. The patients of $30 \%(\mathrm{n}=989)$ received azathioprine, with the maximum proportion being in eastern cohort $(\mathrm{n}=238,91.5 \%)$. Biologics and biosimilars were used in 41 patients (1.3\%), the proportion of these patients was highest in eastern (3.1\%) followed by northern (1.5\%) cohorts. Surgical intervention was needed in 46 patients (1.2\%), most commonly in the northern cohort (2.1\%).

Among the CD cohort, 244 out of 631 patients (38.7\%) were on corticosteroids. Corticosteroid use was noted in a higher proportion of patients in the western (52.9\%) and northern (51.2\%) cohorts than from southern cohort (27.9\%). Use of immunosuppressants (azathioprine) was reported in 340 patients (53.9\%) and biologics in 16 patients (2.5\%). Both these drugs were most commonly used in the southern cohort (azathioprine: $\mathrm{n}=231$, $66.4 \%$; biologics: $\mathrm{n}=14,4.2 \%$ ). Thirty patients (4.8\%) had past history of use of antitubercular therapy, this was reported most commonly from the western cohort $(n=29,24.4 \%)$. A total of

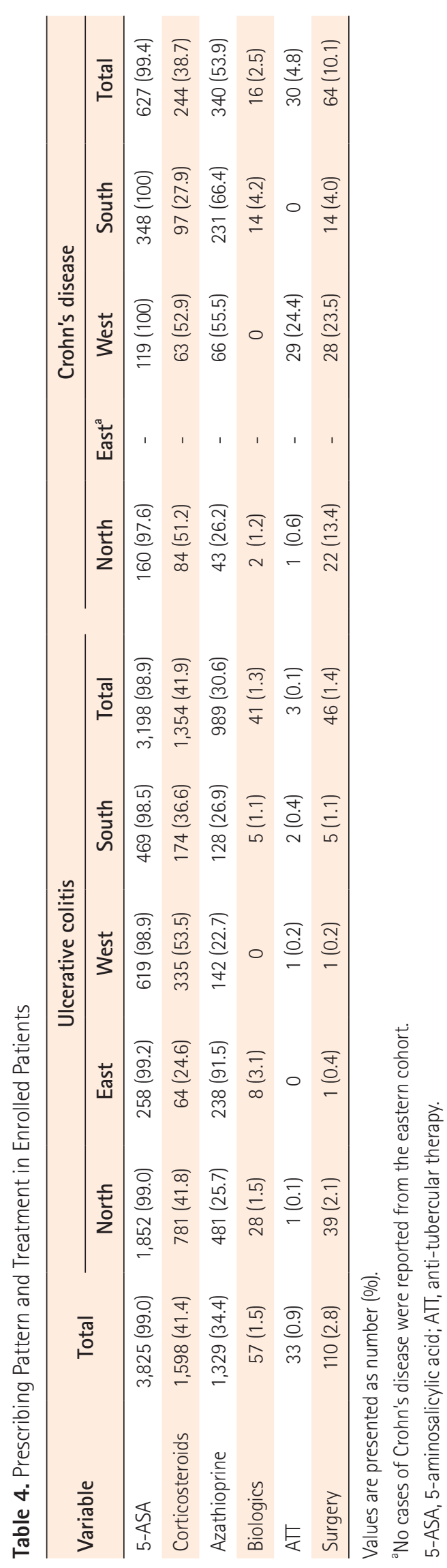


$10.14 \%$ patients underwent surgery for CD, the rates of surgical intervention were highest in the western cohort (23.5\%).

\section{DISCUSSION}

IBD has been increasingly reported from South Asia and South East Asia in the last two decades. Though the prevalence of IBD in India is lesser than that in the West, considering a population of 1.3 billion, the disease burden seems to be the highest worldwide. ${ }^{17}$ Despite the rapidly increasing numbers of IBD patients, there are significant gaps in the knowledge of epidemiology and risk factors. ${ }^{18}$ The present national IBD registry is an attempt to assess the demographic profile of patients from 4 different geographical zones in India.

The results of national IBD registry show significant differences in the demographic profile of the patient cohorts from the 4 geographical regions of India. UC was more common than CD, with a UC:CD ratio of 5.1:1. However, more than half of the UC patients were reported from the northern cohort and a majority of CD patients were from south. This north-south divide lends credence to the potential contribution of environmental (e.g., social, cultural, behavioral) risk factors apart from genetic predisposition. This derives support from the population genetic studies which have demonstrated that: (1) the genomic structure of contemporary Indian populations arose from different proportions of ancestral components namely Ancestral North Indians (ANI), Ancestral South Indians (ASI), Ancestral Austro-Asiatic and Ancestral Tibeto-Burman; (2) North Indians (NI) and South Indians (SI) have a higher proportion of ANI and ASI respectively; (3) ANI show higher genetic affinity with West Eurasians and ASI is distantly related to indigenous Andaman Islanders. ${ }^{19}$ The genetic relatedness between NI and Caucasians is in line with studies wherein shared and unique UC genetic risk has been observed between these 2 populations. ${ }^{20-22}$ Association of autophagy related gene (IRGM gene) SNPs (rs1000113, rs9637876, and rs13361189) with CD has been reported from south India. ${ }^{23}$ A recent study demonstrated similar genetic landscape with most of the common variants shared between NI and SI, however signatures of recent adaptation unique to the 2 study populations were identified, which may have contributed to genetic differentiation of some genomic regions between NI and SI, and resulted in a varying prevalence of genetic disorders or differential susceptibility to diseases in the 2 populations. ${ }^{24}$

India has diverse cultures, religious beliefs, diets and climates. A majority of Sikhs reside in northern states of India. The north- ern cohort therefore had the highest percentage of Sikhs. Sikhism prohibits smoking and the latter has been shown to be a risk factor in development of $\mathrm{CD}^{25,26}$ This may be one of the factors contributing to the lesser prevalence of $\mathrm{CD}$ in the northern cohort. An epidemiological study among South Asian migrants and European residents of Leicestershire has also shown a higher risk of UC among Sikhs and a less risk among Muslims. ${ }^{27}$ Further studies are required to assess genetic and environmental factors in Sikhs which may predispose them to UC. Indian diet is also very diverse and relates to social identity, religion and cultural factors. ${ }^{28,29}$ These differences in diet may in turn result in differences in gut microbial composition and diversity.

The mean age at diagnosis of IBD was $36.7 \pm 13.6$ years and the age distribution was similar in all 4 zones. This was in contradiction to the Western data where IBD has a bimodal age distribution, with a second peak at $60-79$ years. ${ }^{30}$ Also, unlike West where CD presents 5-10 years earlier than UC, the age distribution in our population was similar, i.e. $37.5 \pm 13.2$ years for UC and $35.8 \pm 14.3$ years for $C D{ }^{31}$ A male preponderance was noted for both UC and CD (ratio of male:female was 1.6:1 [UC, 1.5:1 and CD, 2.2:1]). Similar findings have been reported from other Indian and Asian studies. ${ }^{32-35}$ However this is contrary to Western data, where gender distribution is either equal or has slight male preponderance in UC, and a female preponderance is noted in $\mathrm{CD}{ }^{18}$ The male preponderance could be related to higher prevalence of smoking or a socio-referral bias, as in some areas of India females have lesser access to medical care. Family history of IBD was elicited in 3\% IBD patients (UC, 3.1\% and CD, 3.16\%), which was similar to other Indian and Asian studies but strikingly less than the Western data. ${ }^{36-38}$ Given the intertwined effects of genes and environment on complex disorders such as IBD, varied disease presentation in different zones of India could be secondary to the combined role of genetic effects and disease-promoting environment on intra-population variation in UC and CD. This however needs further studies. The rate of perianal disease modifier was very low in this study and this finding was different from other Asian studies. The perianal disease modifier in this registry refers to fistulizing perianal disease, hence lower rates. The fistulizing disease was confirmed by physical examination, fistulograms or MRI pelvis. Some patients of perianal disease may have been missed due to incomplete data from different centers. However, the proportion of these patients is not expected to be high.

The treatment practices in IBD patients were variable in different zones. Though 5-aminosalicylates were administered to 
nearly all patients, the use of immunosuppressants, biologics and surgical intervention varied in different zones. Differentiating intestinal tuberculosis from CD is challenging in developing countries. When in doubt, patients were treated with antitubercular therapy first and were included only if there was no response to anti-tubercular therapy. This is evident from the fact nearly $5 \%$ patients $(n=33)$ with CD had previously been treated with anti-tubercular therapy, the maximum proportion being in the western cohort. Surgical interventions were more commonly required in patients with CD (10.1\%), as compared to UC (1.4\%). Amongst the patients with CD, maximum number of surgeries was reported from the south, probably due to the severest disease in this cohort.

There are a few limitations of our registry. These include the non-inclusion of the follow-up period for treatment responses; limited participation of centers in the eastern and western India and missing data from few centers. The prevalence of IBD in India cannot be calculated due to these limitations. However, despite these limitations, the results of this IBD registry will be very helpful in healthcare decision taking for Indian medical fraternity. It may lay the foundation for a prospectively maintained national IBD registry for the survey of patient demographics and evaluation of the quality of healthcare for IBD patients. In addition to this, this may provide a better understanding of the incidence and progression of the disease in India.

\section{ADDITIONAL INFORMATION}

\section{Funding Source}

The authors received no financial support for the research, authorship, and/or publication of this article.

\section{Conflict of Interest}

Sood A and Puri AS are editorial board members of the journal but did not involve in the peer reviewer selection, evaluation, or decision process of this article. No other potential conflicts of interest relevant to this article were reported.

\section{Author Contribution}

Conception and design: Sood A, Midha V. Supervision, analysis and interpretation of the data: Sood A, Midha V. Collection: Kaur K, Mahajan R, Singh A, Sharma S, Puri AS, Goswami B, Desai D, Pai CG, Peddi K, Philip M, Kochhar R, Nijhawan S, Bhatia S, Rao NS. Drafting of the article: all authors. Critical revision of the article for important intellectual content: all authors. Final approval of the article: all authors.

\section{ORCID}

Sood A

https://orcid.org/0000-0001-6961-6389

Kaur K

Mahajan R

Midha V

Singh A

Sharma S

Puri AS

Desai D

Pai CG

Peddi K

Kochhar R

Bhatia S https://orcid.org/0000-0002-0951-7415 https://orcid.org/0000-0001-6726-6151 https://orcid.org/0000-0003-0192-3969 https://orcid.org/0000-0001-7163-0454 https://orcid.org/0000-0001-8531-492X https://orcid.org/0000-0002-3663-2494 https://orcid.org/0000-0002-9741-5549 https://orcid.org/0000-0003-4676-6282 https://orcid.org/0000-0002-4524-9366 https://orcid.org/0000-0002-4077-6474 https://orcid.org/0000-0001-6132-0356

\section{REFERENCES}

1. Solomon DH, Shadick NA, Weinblatt ME, et al. Clinical patient registry recruitment and retention: a survey of patients in two chronic disease registries. BMC Med Res Methodol 2017;17:59.

2. Bergqvist D, Björck M, Säwe J, Troëng T. Randomized trials or population-based registries. Eur J Vasc Endovasc Surg 2007; 34:253-256.

3. Gordon H, Langholz E. The EpiCom survey: registries across Europe, epidemiological research and beyond. J Crohns Colitis 2017;11:1019-1021.

4. Winter DA, Karolewska-Bochenek K, Lazowska-Przeorek I, et al. Pediatric IBD-unclassified is less common than previously reported; results of an 8-year audit of the EUROKIDS registry. Inflamm Bowel Dis 2015;21:2145-2153.

5. Ng SC, Tang W, Ching JY, et al. Incidence and phenotype of inflammatory bowel disease based on results from the Asiapacific Crohn's and colitis epidemiology study. Gastroenterology 2013;145:158-165.

6. Ahuja V, Tandon RK. Inflammatory bowel disease in the AsiaPacific area: a comparison with developed countries and regional differences. J Dig Dis 2010;11:134-147.

7. Al-Shamali MA, Kalaoui M, Patty I, Hasan F, Khajah A, Al-Nakib B. Ulcerative colitis in Kuwait: a review of 90 cases. Digestion 2003;67:218-224.

8. Tezel A, Dökmeci G, Eskiocak M, Umit H, Soylu AR. Epidemiological features of ulcerative colitis in Trakya, Turkey. J Int Med Res 2003;31:141-148.

9. Niv Y, Abuksis G, Fraser GM. Epidemiology of ulcerative colitis in Israel: a survey of Israeli kibbutz settlements. Am J Gastroenterol 2000;95:693-698. 
10. Das K, Ghoshal UC, Dhali GK, Benjamin J, Ahuja V, Makharia GK. Crohn's disease in India: a multicenter study from a country where tuberculosis is endemic. Dig Dis Sci 2009;54:10991107.

11. Munkholm P, Langholz E, Nielsen OH, Kreiner S, Binder V. Incidence and prevalence of Crohn's disease in the county of Copenhagen, 1962-87: a sixfold increase in incidence. Scand J Gastroenterol 1992;27:609-614.

12. Langholz E, Munkholm P, Nielsen OH, Kreiner S, Binder V. Incidence and prevalence of ulcerative colitis in Copenhagen county from 1962 to 1987. Scand J Gastroenterol 1991;26:12471256.

13. Silverberg MS, Satsangi J, Ahmad T, et al. Toward an integrated clinical, molecular and serological classification of inflammatory bowel disease: report of a Working Party of the 2005 Montreal World Congress of Gastroenterology. Can J Gastroenterol 2005;19 Suppl A:5A-36A.

14. Satsangi J, Silverberg MS, Vermeire S, Colombel JF. The Montreal classification of inflammatory bowel disease: controversies, consensus, and implications. Gut 2006;55:749-753.

15. Schroeder KW, Tremaine WJ, Ilstrup DM. Coated oral 5-aminosalicylic acid therapy for mildly to moderately active ulcerative colitis: a randomized study. N Engl J Med 1987;317:16251629.

16. Harvey RF, Bradshaw JM. A simple index of Crohn's-disease activity. Lancet 1980;1:514.

17. Singh P, Ananthakrishnan A, Ahuja V. Pivot to Asia: inflammatory bowel disease burden. Intest Res 2017;15:138-141.

18. Kedia S, Ahuja V. Epidemiology of inflammatory bowel disease in India: the great shift East. Inflamm Intest Dis 2017;2: 102-115.

19. Basu A, Sarkar-Roy N, Majumder PP. Genomic reconstruction of the history of extant populations of India reveals five distinct ancestral components and a complex structure. Proc Natl Acad Sci U S A 2016;113:1594-1599.

20. Juyal G, Prasad P, Senapati S, et al. An investigation of genomewide studies reported susceptibility loci for ulcerative colitis shows limited replication in north Indians. PLoS One 2011;6: e16565.

21. Juyal G, Negi S, Sood A, et al. Genome-wide association scan in north Indians reveals three novel HLA-independent risk loci for ulcerative colitis. Gut 2015;64:571-579.

22. Liu JZ, van Sommeren S, Huang H, et al. Association analyses identify 38 susceptibility loci for inflammatory bowel disease and highlight shared genetic risk across populations. Nat Genet 2015;47:979-986.
23. Baskaran K, Pugazhendhi S, Ramakrishna BS. Association of IRGM gene mutations with inflammatory bowel disease in the Indian population. PLoS One 2014;9:e106863.

24. Juyal G, Mondal M, Luisi P, et al. Population and genomic lessons from genetic analysis of two Indian populations. Hum Genet 2014;133:1273-1287.

25. To N, Gracie DJ, Ford AC. The importance of smoking cessation in improving disease course in Crohn's disease. Am J Gastroenterol 2016;111:1198.

26. Kuenzig ME, Lee SM, Eksteen B, et al. Smoking influences the need for surgery in patients with the inflammatory bowel diseases: a systematic review and meta-analysis incorporating disease duration. BMC Gastroenterol 2016;16:143.

27. Probert CS, Jayanthi V, Pinder D, Wicks AC, Mayberry JF. Epidemiological study of ulcerative proctocolitis in Indian migrants and the indigenous population of Leicestershire. Gut 1992;33:687-693.

28. Vecchio MG, Paramesh EC, Paramesh H, et al. Types of food and nutrient intake in India: a literature review. Indian J Pediatr 2014;81 Suppl 1:17-22.

29. Green R, Milner J, Joy EJ, Agrawal S, Dangour AD. Dietary patterns in India: a systematic review. Br J Nutr 2016;116:142-148.

30. Sonnenberg A. Age distribution of IBD hospitalization. Inflamm Bowel Dis 2010;16:452-457.

31. Duricova D, Burisch J, Jess T, Gower-Rousseau C, Lakatos PL; ECCO-EpiCom. Age-related differences in presentation and course of inflammatory bowel disease: an update on the population-based literature. J Crohns Colitis 2014;8:1351-1361.

32. Kalaria R, Desai D, Abraham P, Joshi A, Gupta T, Shah S. Temporal change in phenotypic behaviour in patients with Crohn's disease: do Indian patients behave differently from Western and other Asian patients? J Crohns Colitis 2016;10:255-261.

33. Malekzadeh MM, Sima A, Alatab S, et al. Iranian Registry of Crohn's and Colitis: study profile of first nation-wide inflammatory bowel disease registry in Middle East. Intest Res 2019; 17:330-339.

34. Yang SK, Yun S, Kim JH, et al. Epidemiology of inflammatory bowel disease in the Songpa-Kangdong district, Seoul, Korea, 1986-2005: a KASID study. Inflamm Bowel Dis 2008;14:542549.

35. Asakura K, Nishiwaki Y, Inoue N, Hibi T, Watanabe M, Takebayashi T. Prevalence of ulcerative colitis and Crohn's disease in Japan. J Gastroenterol 2009;44:659-665.

36. Makharia GK, Ramakrishna BS, Abraham P, et al. Survey of inflammatory bowel diseases in India. Indian J Gastroenterol 2012;31:299-306. 
37. Ng SC, Leung WK, Shi HY, et al. Epidemiology of inflammatory bowel disease from 1981 to 2014: results from a territorywide population-based registry in Hong Kong. Inflamm Bowel Dis 2016;22:1954-1960.
38. Childers RE, Eluri S, Vazquez C, Weise RM, Bayless TM, Hutfless S. Family history of inflammatory bowel disease among patients with ulcerative colitis: a systematic review and metaanalysis. J Crohns Colitis 2014;8:1480-1497. 